\title{
Air void analysis of hardened concrete without colour enhancement
}

\author{
Li, Gui; Hasholt, M.T.; Jensen, O.M.
}

Published in:

Concrete Durability and Service Life Planning

Link to article, DOI:

10.1007/978-3-030-43332-1_16

Publication date:

2020

Document Version

Peer reviewed version

Link back to DTU Orbit

Citation (APA):

Li, G., Hasholt, M. T., \& Jensen, O. M. (2020). Air void analysis of hardened concrete without colour enhancement. In Concrete Durability and Service Life Planning: Proceedings of ConcreteLife'20 (Vol. 26, pp. 7983). Springer. RILEM Bookseries https://doi.org/10.1007/978-3-030-43332-1_16

\section{General rights}

Copyright and moral rights for the publications made accessible in the public portal are retained by the authors and/or other copyright owners and it is a condition of accessing publications that users recognise and abide by the legal requirements associated with these rights.

- Users may download and print one copy of any publication from the public portal for the purpose of private study or research.

- You may not further distribute the material or use it for any profit-making activity or commercial gain

- You may freely distribute the URL identifying the publication in the public portal

If you believe that this document breaches copyright please contact us providing details, and we will remove access to the work immediately and investigate your claim. 


\section{Metadata of the chapter that will be visualized in SpringerLink}

\begin{tabular}{|c|c|c|}
\hline Book Title & \multicolumn{2}{|c|}{ Concrete Durability and Service Life Planning } \\
\hline \multicolumn{3}{|l|}{ Series Title } \\
\hline Chapter Title & \multicolumn{2}{|c|}{ Air Void Analysis of Hardened Concrete Without Colour Enhancement } \\
\hline Copyright Year & \multicolumn{2}{|l|}{2020} \\
\hline Copyright HolderName & \multicolumn{2}{|l|}{ RILEM } \\
\hline \multirow[t]{10}{*}{ Corresponding Author } & Family Name & $\mathbf{L i}$ \\
\hline & Particle & \\
\hline & Given Name & Gui \\
\hline & Prefix & \\
\hline & Suffix & \\
\hline & Role & \\
\hline & Division & Department of Civil Engineering \\
\hline & Organization & Technical University of Denmark \\
\hline & Address & Lyngby, Denmark \\
\hline & Email & guili@byg.dtu.dk \\
\hline \multirow[t]{10}{*}{ Author } & Family Name & Hasholt \\
\hline & Particle & \\
\hline & Given Name & M. T. \\
\hline & Prefix & \\
\hline & Suffix & \\
\hline & Role & \\
\hline & Division & Department of Civil Engineering \\
\hline & Organization & Technical University of Denmark \\
\hline & Address & Lyngby, Denmark \\
\hline & Email & \\
\hline \multirow[t]{10}{*}{ Author } & Family Name & Jensen \\
\hline & Particle & \\
\hline & Given Name & O. M. \\
\hline & Prefix & \\
\hline & Suffix & \\
\hline & Role & \\
\hline & Division & Department of Civil Engineering \\
\hline & Organization & Technical University of Denmark \\
\hline & Address & Lyngby, Denmark \\
\hline & Email & \\
\hline Abstract & \multicolumn{2}{|c|}{$\begin{array}{l}\text { Air void structure plays a key role in the durability of concrete structures in cold regions. This is because } \\
\text { water in the microstructure can escape into the air voids which, thereby, effectively reduce the stresses } \\
\text { during cyclic freezing and thawing. This protects the concrete structures from developing frost damage [1, } \\
\text { 2]. Therefore, to assure the frost resistance of conventional concrete, it is necessary to quantify its air void } \\
\text { structure. }\end{array}$} \\
\hline Keywords & \multicolumn{2}{|c|}{ Air void analysis - Hardened concrete - Optical microscopy - Shape From Focus (SFF) - Focused image } \\
\hline
\end{tabular}




\title{
Air Void Analysis of Hardened Concrete Without Colour Enhancement
}

\author{
Gui Li ${ }^{(\bowtie)}$, M. T. Hasholt, and O. M. Jensen \\ Department of Civil Engineering, \\ Technical University of Denmark, Lyngby, Denmark \\ guili@byg.dtu.dk
}

\begin{abstract}
Keywords: Air void analysis $\cdot$ Hardened concrete $\cdot$ Optical microscopy $\cdot$ Shape From Focus (SFF) · Focused image
\end{abstract}

\section{Introduction}

Air void structure plays a key role in the durability of concrete structures in cold regions. This is because water in the microstructure can escape into the air voids which, thereby, effectively reduce the stresses during cyclic freezing and thawing. This protects the concrete structures from developing frost damage [1, 2]. Therefore, to assure the frost resistance of conventional concrete, it is necessary to quantify its air void structure.

The most widely used methods for measuring the air void parameters in hardened concrete are the microscopy-based methods described in ASTM C457/457M-16 [3]. The linear-traverse method determines the air void parameters by analysing the data that include the number of air voids traversed by a set of regularly spaced lines and the distances traversed through paste and air voids along these lines. The modified pointcount method counts the number of air voids traversed through the lines as well, but instead of summing the traverse distances, a grid of points is used to record the frequency of locations in paste and air voids. Both methods can be conducted manually, but this is time-consuming, tedious and expensive. In addition, the results can be influenced by operator judgment. To address these drawbacks, the contrast-enhanced methodscan be used to identify the air voids by image analysis. Then colour enhancement needs to be done before the microscopy analysis. This also needs significant efforts for sample preparation. Furthermore, the quality of surface treatment can influence the accuracy of test results [4].

In the 1990s, Nayar [5] developed a shape from focus method to analyse the texture of different objects that have a rough surface. An optical microscope is used to get a sequence of images with different focus planes. Then the focused image and 3D texture of the object surface can be reconstructed and the depth map can be computed. In the present study, the shape from focus method is used to obtain the focused image and the depth information of the concrete surface. This enables automatic identification of the air void structure in hardened concrete, without pre-treatment like colour enhancement. 


\section{The Principle of a New Test Method: Shape from Focus (SFF)}

Before introducing the principle of the shape from focus method (SFF), the image formation process should be kept in mind. As shown in Fig. 1, when the light rays radiated by a point pass through the lens, they are refracted and converged at a single point. For a thin lens, the relationship between the focal length of the lens $f$, the distance from the point to the lens plane $o$, and the distance from the image plane to the lens plane $i$, follow the Gaussian lens law [5]:

$$
\frac{1}{o}+\frac{1}{i}=\frac{1}{f}
$$

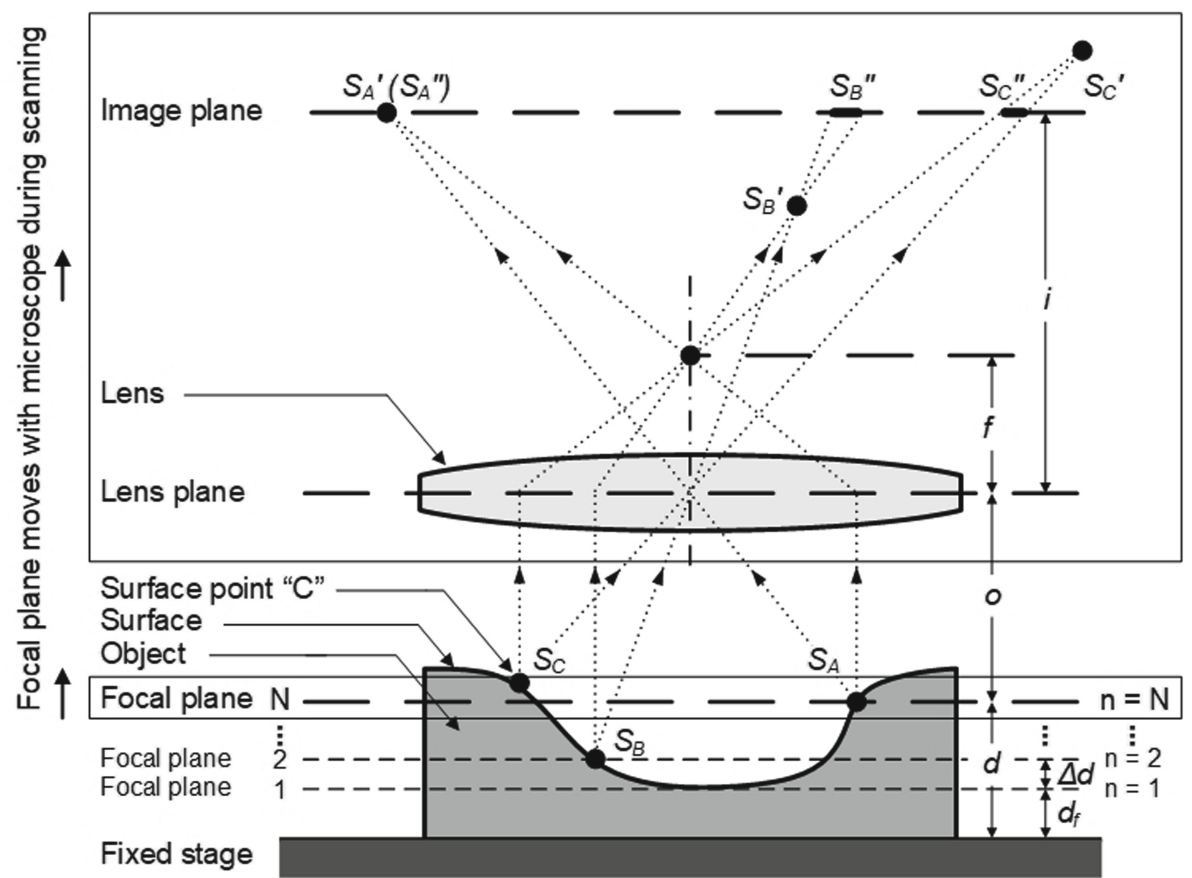

Fig. 1. Principle of the image formation and the shape from focus method. (Note: The microscope can be moved from top to bottom as well.)

Therefore, for an optical microscope system, when the configuration of the lens plane and the image plane is fixed, the only focal plane is defined, see Fig. 1. It means that only the surface points that lie on the focal plane (like $S_{A}$ ) will be perfectly focused on the image plane. Other points located outside the focal plane (like $S_{B}$ and $S_{C}$ ) will form defocused or blurred areas on the image plane $\left(S_{B}^{\prime \prime}\right.$ and $\left.S_{C}^{\prime \prime}\right)$. 
Based on this, when an object with a rough surface is placed on a fixed stage, moving the focal plane away from the stage by moving the microscope allows getting the focused image of each point located in different positions, as presented in Fig. 1. For each point on the object surface, it is possible to determine its degree of focus in different image frames by using a focus measure operator and then record the displacement of the microscope at the position of maximum focus. After that, the height of the point with respect to the stage $d$ can be calculated by Eq. (2):

$$
d=d_{f}+(n-1) \Delta d
$$

Where $\mathrm{d}_{f}$ is the distance between the initial position of the focal plane $(n=1)$ and the fixed stage, which can be measured directly, $n$ is the number of steps, and $\Delta d$ is the displacement of the microscope at each step. This procedure allows determining of the height of all points with respect to the stage independently to get the focused image and the depth map of the entiresurface. And it can also be used to calculate the distance between all points and other planes such as the lens plane.

\section{Materials and Methods}

\subsection{Sample Preparation}

A concrete sample was prepared using Portland cement CEM I $52.5 \mathrm{~N}$, sea sand, and crushed granite (4-16 mm). Instead of traditional air entraining agents, suspension polymerized superabsorbent polymers (SAP) was used to create the air void structure in the hardened concrete. The total w/c was 0.52 , and the SAP dosage was $0.4 \%$ relative to the mass of cement. The SAP absorption capacity was $17 \mathrm{~g} / \mathrm{g}$. The percentage by volume of sand and coarse aggregate was approx. $23 \%$ and $35 \%$, respectively. The sample was cast in a cylindrical mould $(\varnothing 150 \mathrm{~mm} \times 300 \mathrm{~mm})$ and demoulded after $24 \mathrm{~h}$. Then the sample was cured in a polythene bag at $20 \pm 1{ }^{\circ} \mathrm{C} 14$ days after mixing, a $20 \pm 1 \mathrm{~mm}$ thick specimen was cut from the cylinder perpendicular to the end surfaces. Finally, the surface of the specimen was ground with successively finer silicon carbide abrasive papers (grit sizes corresponding to $75,35,17.5$ and $12.5 \mu \mathrm{m}$ ).

\subsection{Image Acquisition and Preliminary Analysis}

A Nikon SMZ25 stereo microscope equipped with NIS-Elements software was used. The specimen was placed on the fixed microscope stage and adjusted, so the test surface was horizontal. The magnification was $70 \times$ (obtained by an objective lens with the magnification of $2 \times$ and azoom of $35 \times)$. After setting the displacement of the microscope $(\Delta d=10 \mu \mathrm{m})$ and the number of steps $(n=51)$, the program digitized and stored images at each position.

The NIS-Elements software was used to obtain the preliminary results, see Fig. 2. The software module is based on the so-called extended depth of focus method (EDF), instead of the shape from focus method. The principle of EDF is different from that of SFF, but both methodscan be used to obtain the focused image and the depth 
information of the object surface [6]. As shown in Fig. 2 left, it is impossible, without colour enhancement, to distinguish air voids from aggregates by using traditional threshold segmentation methods directly. However, due to the difference of depth between air voids and the rest of the test surface, air voids can be identified from the depth map presented in Fig. 2 centre via a threshold segmentation method, see Fig. 2 right. Thus, preliminary results illustrate that it is generally possible to distinguish air voids from aggregates based on the depth information. However, some air voids are not detected, and this is the topic for further investigations.
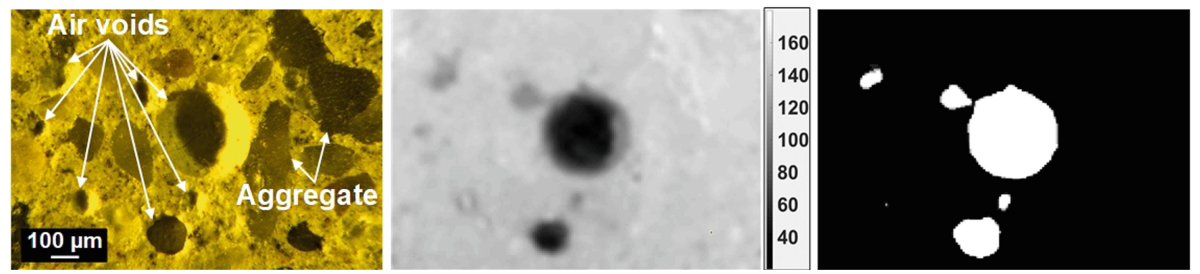

Fig. 2. Images obtained by the NIS-Elements software in the microscope system. Left: focused image; centre: depth map; right: binary image.

\subsection{Upcoming Work}

In the near future, the SSF method will be used to process and analyse microscopeimages. After image acquisition, a modified Laplacian focus measure operator is used to determine the degree of focus of each pixel [5]. Based on this, the image frame with the maximum sharpness measure at each pixel is determined. After that, the focused image and depth map of the concrete surface can be obtained to enable analysis of the air void structure of hardened concrete.

To test the accuracy and robustness of the SFF method, a comparison between the results obtained by the SFF method and that of the modified point-count method will be performed. A study will also be conducted on influencing factors including the brightness and resolution of images, the number and magnitude of the displacement steps, the smoothness of the specimen surface, etc.

Acknowledgement. The authors would like to thank China Scholarship Council and Technical University of Denmark for funding this research project. Shengying Zhao, guest $\mathrm{PhD}$ student at Technical University of Denmark, provided the polished specimen, and this is also acknowledged.

\section{References}

1. Powers, T.C.: The air requirement of frost resistant concrete. Proc. Highw. Res. Board 29, 184-221 (1949)

2. Pigeon, M., Pleau, R.: Durability of Concrete in Cold Climates. CRC Press, Boca Raton (1995). Spon 
3. ASTM C457/C457M-16: Standard Test Method for Microscopical Determination of Parameters of the Air-Void System in Hardened Concrete. ASTM International, West Conshohocken, PA (2016)

4. Pleau, R., Michel, P., Jean, L.L.: Some findings on the usefulness of image analysis for determining the characteristics of the air-void system on hardened concrete. Cem. Concr. Compos. 23(2-3), 237-246 (2001)

5. Nayar, S.K.: Shape from focus system. In: IEEE Computer Society Conference on Computer Vision and Pattern Recognition (1992)

6. Zalevsky, Z.: Extended depth of focus imaging: a review. SPIE Rev. 1(1), 018001 (2010) 


\section{Author Query Form}

Book ID : 496482_1_En

Chapter No : 16

Please ensure you fill out your response to the queries raised below and return this form along with your corrections.

Dear Author,

During the process of typesetting your chapter, the following queries have arisen. Please check your typeset proof carefully against the queries listed below and mark the necessary changes either directly on the proof/online grid or in the 'Author's response' area provided below

\begin{tabular}{|l|l|r|}
\hline Query Refs. & Details Required & Author's Response \\
\hline AQ1 & $\begin{array}{l}\text { Please confirm if the corresponding author is correctly identified. Amend if } \\
\text { necessary. }\end{array}$ & \\
\hline
\end{tabular}




\section{Please correct and return this set}

Please use the proof correction marks shown below for all alterations and corrections. If you wish to return your proof by fax you should ensure that all amendments are written clearly in dark ink and are made well within the page margins.

\begin{tabular}{|c|c|c|}
\hline Instruction to printer & Textual mark & Marginal mark \\
\hline Leave unchanged & ... under matter to remain & ( $)$ \\
\hline $\begin{array}{l}\text { Insert in text the matter } \\
\text { indicated in the margin }\end{array}$ & $\Lambda$ & $\begin{array}{l}\text { New matter followed by } \\
h \text { or } h \otimes\end{array}$ \\
\hline Delete & $\begin{array}{l}\text { I through single character, rule or underline } \\
\text { or }\end{array}$ & $\sigma$ or $\sigma / 2$ \\
\hline $\begin{array}{l}\text { Substitute character or } \\
\text { substitute part of one or } \\
\text { more word(s) }\end{array}$ & I through letter or & $\begin{array}{l}\text { new character / or } \\
\text { new characters / }\end{array}$ \\
\hline Change to italics & — under matter to be changed & $\leftarrow$ \\
\hline Change to capitals & $\equiv$ under matter to be changed & $\equiv$ \\
\hline Change to small capitals & $=$ under matter to be changed & $=$ \\
\hline Change to bold type & $\sim$ under matter to be changed & $\sim$ \\
\hline Change to bold italic & $\bar{\sim}$ under matter to be changed & 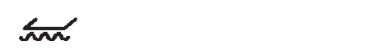 \\
\hline Change to lower case & Encircle matter to be changed & $\Rightarrow$ \\
\hline Change italic to upright type & (As above) & \\
\hline Change bold to non-bold type & (As above) & nor \\
\hline Insert 'superior' character & $\begin{array}{l}/ \text { through character or } \\
\alpha \text { where required }\end{array}$ & $\begin{array}{l}y^{\prime} \text { or } y \\
\text { under character } \\
\text { e.g. } y^{2} \text { or } y^{2}\end{array}$ \\
\hline Insert 'inferior' character & (As above) & $\begin{array}{l}\lambda \\
\text { over character } \\
\text { e.g. } \hat{\Sigma}\end{array}$ \\
\hline Insert full stop & (As above) & $\odot$ \\
\hline Insert comma & (As above) & , \\
\hline Insert single quotation marks & (As above) & $\begin{array}{l}\dot{y} \text { or } \dot{x} \text { and/or } \\
\dot{y} \text { or } \dot{y}\end{array}$ \\
\hline Insert double quotation marks & (As above) & $\begin{array}{l}\ddot{y} \text { or } \ddot{x} \text { and/or } \\
\ddot{y} \text { or } \ddot{x}\end{array}$ \\
\hline Insert hyphen & (As above) & 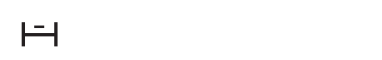 \\
\hline Start new paragraph & 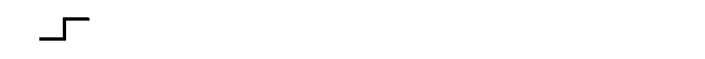 & 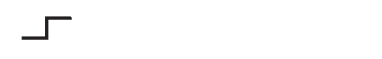 \\
\hline No new paragraph & 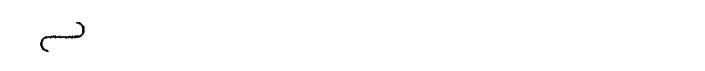 & 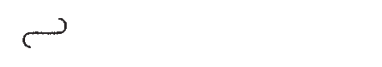 \\
\hline Transpose & $\sqcup$ & $\sqcup$ \\
\hline Close up & linking $\bigcirc$ characters & \\
\hline $\begin{array}{l}\text { Insert or substitute space } \\
\text { between characters or words }\end{array}$ & $\begin{array}{l}\text { I through character or } \\
\Lambda \text { where required }\end{array}$ & \\
\hline $\begin{array}{l}\text { Reduce space between } \\
\text { characters or words }\end{array}$ & $\begin{array}{l}\text { between characters or } \\
\text { words affected }\end{array}$ & $\uparrow$ \\
\hline
\end{tabular}

